\title{
Modelling urban growth for Bangkok and assessing linkages with road density and socio- economic indicators
}

\author{
Shankar Acharya Kamarajugedda ${ }^{1,2,4, *}$, Edmond Y.M. Lo ${ }^{2,3,4}$ \\ ${ }^{1}$ Interdisciplinary Graduate Programme, Nanyang Technological University, Singapore - shankara003@e.ntu.edu.sg \\ ${ }^{2}$ Institute of Catastrophe Risk Management, Nanyang Technological University, Singapore \\ ${ }^{3}$ School of Civil and Environmental Engineering, Nanyang Technological University, Singapore - cymlo@ntu.edu.sg \\ ${ }^{4}$ Future Resilient Systems, Singapore-ETH Centre, Singapore
}

\section{Commission IV}

KEY WORDS: Remote Sensing, Urbanization, Road Density, Population, SLEUTH, Zoning Maps

\begin{abstract}
:
The fastest urbanization is occurring in the Global South which includes many developing nations in Asia. However, a rapid and unplanned urban growth could threaten the sustainability of the process. A key step towards a sustainable urban development is to better understand interdependencies amongst urban growth patterns, infrastructure and socio-economic indicators. Here we chose Bangkok, Thailand as a megacity case study to assess the spatio-temporal urban growth dynamics and specifically its dependency with road density at intra-city scales. The SLEUTH urban growth model is further applied for predicting future expansion over the next decade and to assess the future intra-city expansion. Urban expansion patterns for Bangkok were generated for 1987 and 2017 using Landsat derived urban land-cover maps. Open Street Map (OSM) is used to generate a 2017 road density map. The urban expansion (1987-2017) was observed to follow a radially outward expanding pattern inland, with the logarithmic urban expansion rate having an inverted concave trend with road density. The rising/falling limbs then indicated an increase/decrease of urban expansion for which a road density "turning point" is readily identified and further used to develop a road density-based zoning map that highlights the different intra-city urban expansion rates. The SLEUTH predicted urban growth till year 2027 which also showed expansion outward from existing urban areas. The future expansion trend is also consistent with the turning point trend. This study showed that such spatial-temporal analysis of urban expansion coupled with SLEUTH can be useful for investigating likely outcomes of city development plans.
\end{abstract}

\section{INTRODUCTION}

The coming decades is expected to witness a major shift in the distribution of global population from rural to urban with the projected urban population to comprise around $66 \%$ of the world's population by 2050 (UNPD, 2018). The world's urban population is expected to rise by 2.5 billion over 2014 to 2050 , with nearly 90 percent of the increase concentrated in Asia and Africa (UNPD, 2018). Corresponding global urban extent is predicted to double by year 2025 when compared to 1996 (Bishop et al., 2000). Seto et al., (2011) further estimated that by year 2030, global land urbanized is estimated to increase by at least 430,000 sq.km from its existing 2000 value of $~ 308,000$ sq.km. Asia and Southeast Asia (SEA), in particular, have given rise to major megacities (population over 10 million), such as Bangkok, Jakarta, and Manila. All these imply large and rapid urbanization with huge demands for increased urban residential, commercial and industrial areas along with infrastructures.

Urbanization if properly planned and managed, brings important benefits to society and to the development of nations. Cities play an outsized role in their generation of economic activity accounting for $80 \%$ of the world GDP and underpinning the backbone of world trade (UNPD, 2018). Urbanization and sustainable development further have a synergistic relationship. Urbanization generally has a positive impact on economic and societal development as people are being drawn to cities in search for better livelihoods. Whilst proper planning of urban growth could lead to favorable economic and social development, rapid and unplanned growth could threaten the sustainability of the development process with impacting negatively on hydrological systems, biodiversity and indeed the global environment. These negative risks further increase with increasing urbanization, e.g. urban expansion into vegetated lands could alter the carbon flux (Seto et al., 2012; Zhou et al., 2013), threatening biodiversity, and impacting on climate change (Triantakonstantis and Mountrakis, 2012). Figure 1, as adapted from the World Economic Forum Global risks perception survey of 2014, shows that failure of urban planning as arising from inadequate or poorly planned national infrastructure is the major risk in SEA. This is amongst the risks faced which includes terrorist risk and water crisis. Hence, properly planned infrastructure alongside urbanization is vital in the urbanization process. An important step towards this is to better understand and model interdependencies amongst urban growth, infrastructure and socio-economic indicators.

Socio-economic data covering GDP and population are good data sources for urbanization studies (Chen et al., 2014; Henderson, 2003; Pumain, 2004). Population is often the main parameter used as a proxy to measure urban growth as assessed via the rate of population change and/or population density change with time. However, such data is frequently unavailable at the required spatial and temporal resolutions in many less-developed and developing nations (Masek et al., 2000) for which remotely sensed (RS) data can be a viable alternative, providing data at multiple spatial and temporal scales. Optical RS data, especially the Landsat data has been widely incorporated to analyze land use/land cover changes as well as urban growth dynamics at global and regional scales (Almazroui et al., 2017; Bhatta, 2009; Subasinghe et al., 2016; Wilson et al., 2003; Yang, 2002). Other sources of RS data, mainly the Night-Time Lights (NTL) and Visible Infrared Imaging Radiometer Suite (VIIRS) data, have also been frequently used for assessing urban growth at global and regional scales because of their direct relevance to anthropogenic activities (Elvidge et al., 2014; Imhoff et al., 1997; 
Kamarajugedda et al., 2017; Liu et al., 2012; Ma et al., 2015; Pandey et al., 2013; Zhao et al., 2018). However, most reported studies on assessing urbanization dynamics using RS data are for the regions of US, Europe, China and India (Batty, 2007; Catalán et al., 2008; Cauwels et al., 2014; Chand et al., 2009; Herold et al., 2003; Liu et al., 2012; Pandey et al., 2013) with very few for SEA cities. Also, road density has been reported as an important index in understanding and analyzing complex urban developmental patterns (Strano et al., 2012; Zhang et al., 2015).

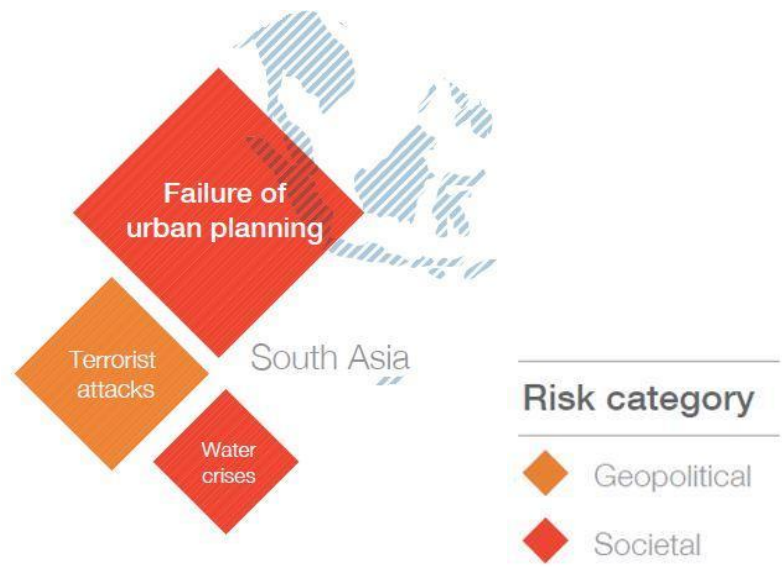

Figure 1. SEA risk perception survey map (Adapted from Global risks perception survey 2014, World Economic Forum)

Urban growth prediction can be performed at scales spanning global, regional or city as depending on the level of data availability. However, growth predication at city and intra-city scale have inherent higher uncertainty as cities are complex systems with intra-city growth dynamics. Various urban growth prediction models (UGPM) are developed with the most common being linear/logistic regression, agent-based, and Cellular Automata (CA) models, and with CA models being increasingly used (Santé et al., 2010). A review paper on UGPM by Triantakonstantis and Mountrakis (2012) reported that out of 156 manuscripts by different researchers, almost $83 \%$ used the CA model for urban growth predication. The SLEUTH (slope, landuse, exclusion, urban extent, transportation and hillshade) is one commonly used CA-based UGPM with many reported studies (Al-shalabi et al., 2013; Bihamta et al., 2015; Clarke and Gaydos, 1998; Herold et al., 2003; Mallouk et al., 2019; Saxena and Jat, 2019). In the SLEUTH model, urban growth rules are applied on a cell-by-cell within a uniform geographical lattice thus making it highly ideal for spatial growth predictions. The dataset used by SLEUTH at its initial time period has a set of growth parameters and probabilities, as determined via calibration using historical urban growth data. This initial, or starting 'seed' layer is used to generate growth over time with each cell acting independently, and growth patterns emerging (Clarke and Gaydos, 1998).

In this work, we use Bangkok as a demonstration study megacity to assess the spatio-temporal interdependencies amongst urban growth, infrastructure and socio-economic indicators, and via SLEUTH to further predict the future expansion pattern during the next decade. Specifically, we quantified Bangkok's urban areal and population expansion rates over decadal time scales (year 1987 to 2017) and delineated the intra-city expansion trend based on deduced road density grades, as representing different levels of infrastructure. A turning point in road density is further identified wherein the expansion rate is larger before the turning point value but slower thereafter. Via SLEUTH, we further projected the urban expanded areas to year 2027 wherein we show that the derived urban expansion trends with road density similarly holds. This study thus represents one of the few very reported at intra-city scales and especially for SEA cities (e.g. Zhao et al. (2017) reported on a similar study for Beijing, New York, London and Chicago). As such our results and similar results from other studies should be find use towards guiding urban development planning.

\section{MATERIALS AND METHODS}

\subsection{Study area}

Bangkok metropolis is one of the largest cities in Southeast Asia with population of over 5 million. More than half of the population in the larger Bangkok metropolitan region, which comprises of Bangkok metropolis and 5 adjacent provinces, lives in Bangkok metropolis with a high population density of around 5258 people $/ \mathrm{km}^{2}$ (Losiri et al., 2016). About 97 percent of the Gross Regional Product (GRP) of the Bangkok metropolitan region is further generated by Bangkok metropolis (Losiri et al., 2016) and Bangkok is reported to have around 19,705 USD per capita economic output (Florida and Fasche, 2017). Figure 2 shows the Bangkok metropolis region used in our study with administrative boundary as downloaded from www.gadm.org. The general urbanization pattern in the Bangkok metropolis or city (the term city is used hereafter to denote metropolis) was found along the Chao Phraya River which then expanded along the transportation network with centers of smaller urban clusters.

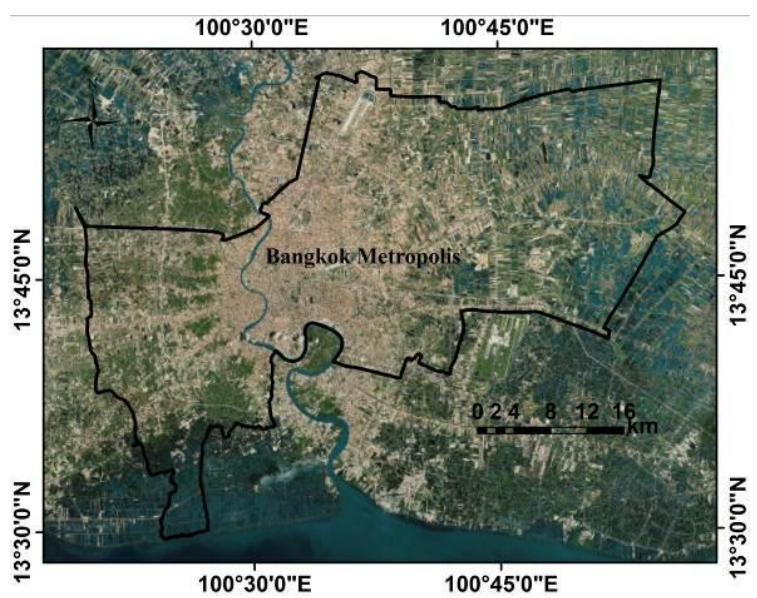

Figure 2. Bangkok metropolis area (boundary highlighted in black)

\subsection{Datasets used}

We used the United States Geological Survey (USGS) remotely sensed Landsat satellite data to analyze urban growth for Bangkok city over a three decadal range. Landsat Thematic Mapper (TM) and Operational Land Imager (OLI) sensors provide multi-spectral data at $30 \mathrm{~m}$ spatial resolution and are operational since 1982. Landsat data for Bangkok was obtained for two years of 1987 and 2017 as downloaded using the USGS earth explorer website (http://earthexplorer.usgs.gov/) and with selected images having less than $10 \%$ cloud cover. For the SLEUTH model development Landsat data for two additional years of 1997 and 2007 was included as needed for model calibration.

The gridded population of the world version 4 (GPWv4) dataset developed by the Center for International Earth Science 
Information Network (CEISIN) 2017, was used to extract population density data for Bangkok. This gridded dataset has a spatial resolution of 30 arc seconds ( $\sim \mathrm{km}$ at equator). The data is available for years $2000,2005,2010,2015$ with a projection to year 2020 . We used the UN adjusted GPWv4 population density datasets for years 2000 and 2015. Lastly, Open Street Map (OSM) polyline road network data for Bangkok for year 2017 was obtained from http://download.geofabrik.de as licensed under www.openstreetmap.org.

\subsection{Methodology}

The methodology comprises: 1) Assessing urban expansion between 1987 and 2017 and developing correlations amongst urban expansion, road density and population at intra-city level; 2) Developing urban growth prediction model using SLEUTH for future urban expansion for Bangkok metropolis.

\subsubsection{Urban expansion and correlation analysis}

The Maximum Likelihood classifier in ArcGIS 10.0 software was used to classify the Landsat imagery into four major classes comprising urban, water body, vegetation and barren land. Training samples needed in the supervised classification were selected via visual inspection. The validation were performed using another 200 independently generated ground truth points selected with the aid of satellite imagery, google earth and topographic maps. A minimum of $85 \%$ in overall accuracy, defined as percentage correct in urban plus non-urban classification, was achieved for the land cover classified maps. Spatial overlay analysis was performed to extract the urban expansion map of Bangkok between 1987 and 2017 and the result shown in Figure 3.

\section{Bangkok}

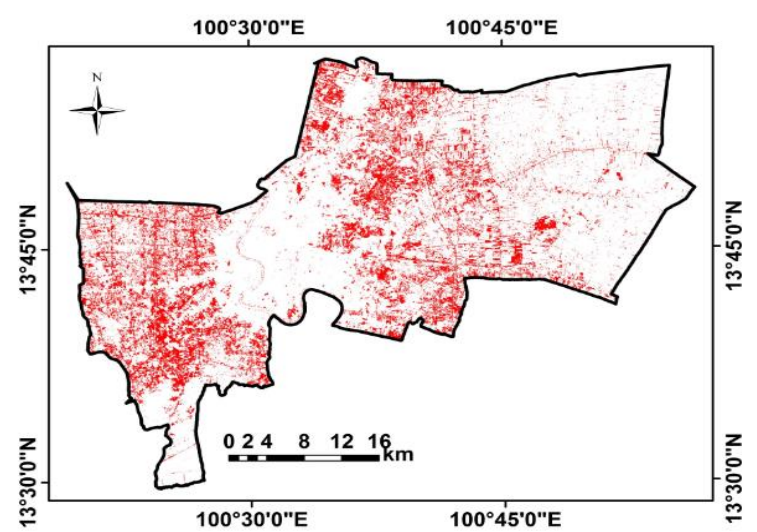

Figure 3. Urban expansion map - red pixels indicate new urban areas formed between 1987 and 2017

The gridded UN adjusted GPWv4 population density values for years 2000 and 2015 were used to derive a population density change map over the 15 years, which was then resampled to Landsat data spatial resolution of $30 \mathrm{~m}$ for maintaining spatial uniformity in intra-city analysis.

Kernel density analysis using ArcGIS 10.0 software was performed on the road network vector shapefile to generate a road density map. Here road density is defined as the ratio of the total length of the centerline of roads to the land area (i.e. units of $\mathrm{km} / \mathrm{km}^{2}$ ). The road density map was generated at $30 \mathrm{~m}$ spatial resolution similar to Landsat data and classified using Jenks natural break algorithm into 5 grades. The road density map for Bangkok is shown in Figure 4.

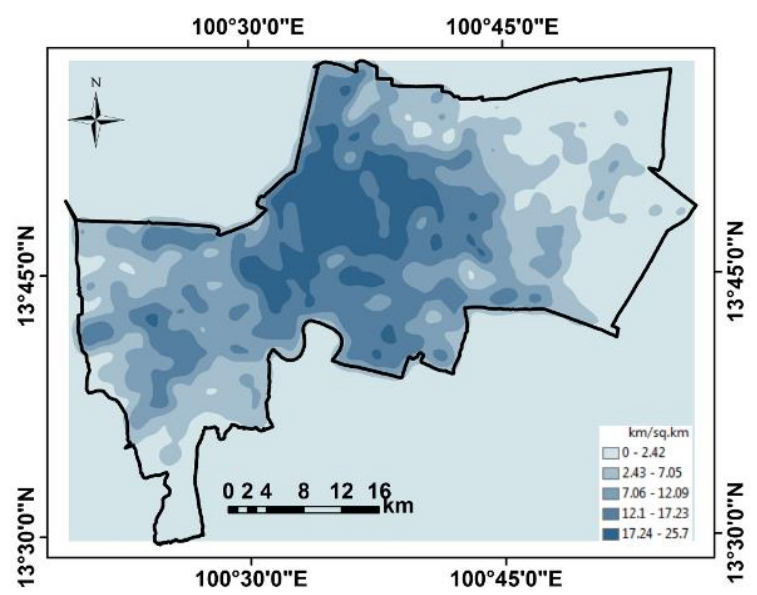

Figure 4. Road density map for Bangkok

Spatial overlay analysis was firstly performed between the generated urban expansion, road density and population growth maps. The urban expanded pixels over 1987 to 2017 were converted to vector shapefile (points) and with the corresponding road density and population growth values extracted. Regression analysis was then applied to assess the linkage between urban expansion rate or population growth rate (specifically the logarithm of the expansion/growth rates) with road density as following Zhao et al. (2017).

As discussed later, an inverted (downward) concave pattern was observed for the logarithm of the expansion/growth rates with road density, which was then fitted using a third-order polynomial (equation (1)). A "turning Point" (equation (2)) as coined by Zhao et al. (2017) at which the slope is zero was identified.

$\log _{10} y=b_{0}+b_{1} x+b_{2} x^{2}+b_{3} x^{3}$

Turning point $x=\frac{-b_{2}-\sqrt{b_{2}^{2}-3 b_{1} b_{3}}}{3 b_{3}}$

where $y=$ urban expansion rate

$x=$ road density

$b_{0}, b_{1}, b_{2}$ and $b_{3}=$ coefficients of the fitted polynomial

Based on the turning point value, a zoning map was developed that classified the different developmental status of the zones.

\subsubsection{SLEUTH model for Bangkok}

The SLEUTH model requires the following datasets to predict the future urban growth scenarios: historical urban extent maps (at least four urban layers for model calibration), digital elevation model (DEM), road networks (at least two years) and an exclusion layer. Two additional Landsat imagery for years 1997 and 2007 were similarly processed to provide the four urban layers needed. The exclusion layer indicates where urban growth cannot take place. Hillshade layer and slope layers were derived from the DEM. While the slope layer is used for SLEUTH's lattice prediction probability computation, the hillshade layer is mainly used as a background layer to add lustre to the mapped results. Also, it is noted that SLEUTH does not take into 
consideration the socio-economic and political factors in its urban growth prediction. The two road layers used were 1987 and 2017. The 1987 road layer derived from Landsat image by visual digitization and thus is at a lower accuracy than the 2017 layer from OSM.

SLEUTH model comprises of three modules mainly: test, calibrate and predict. The general SLEUTH model structure is shown in Figure 5.

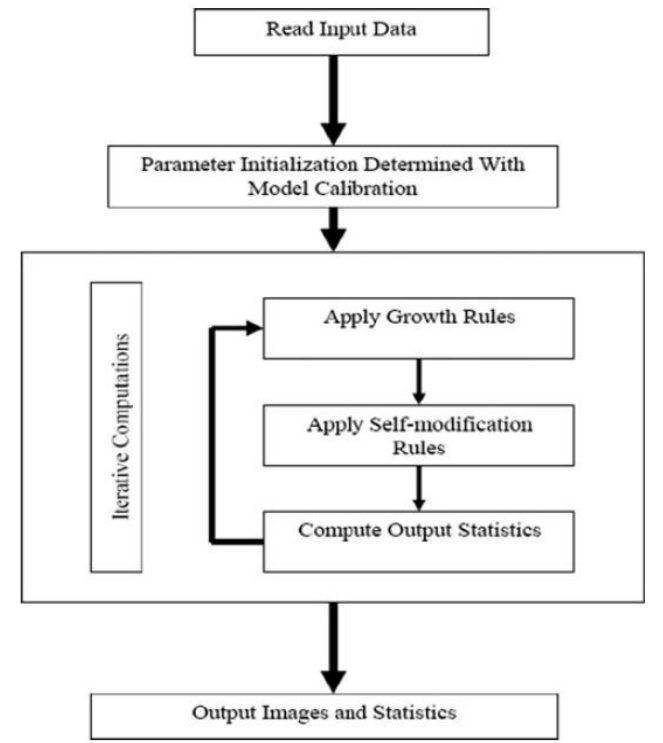

Figure 5. General structure of a SLEUTH model (Source: Alshalabi et al. 2013)

SLEUTH's dynamic urban growth is described by four rules: spreading center, edge growth, and road influenced growth. The growth rules correspond to a set of coefficients with values ranging from 0 to 100 , and which indicate how much influence the different growth rules have across the study area. There are five factors which control the behavior of the urban growth model: diffusion factor, breed coefficient, spread coefficient, slope coefficient, and road-gravity factor. The relationship between these five coefficients and growth rules is represented in Table 1.

SLEUTH model calibration is run over three phases of increasing spatial resolution, i.e., coarse, fine and final. The input layers were prepared according to respective spatial resolutions in GIF format, specifically, $120 \mathrm{~m}, 60 \mathrm{~m}$ and $30 \mathrm{~m}$ for coarse, fine and final resolutions, respectively. Calibration of SLEUTH is the most important step for capturing urban growth pattern trends and so allow a forecasting based on the trend. During calibration best-fit values for the five growth control parameters (Table 1) are chosen as best fitting the historical urban extent data based on statistical measures.

\begin{tabular}{|l|l|l|l|}
\hline $\begin{array}{l}\text { Growth } \\
\text { cycle order }\end{array}$ & Growth type & $\begin{array}{l}\text { Controlling } \\
\text { coefficients }\end{array}$ & Summary description \\
\hline 1 & spontaneous & dispersion & Randomly selects potential new growth cells. \\
\hline 2 & $\begin{array}{l}\text { new spreading } \\
\text { centre (diffusive) }\end{array}$ & breed & $\begin{array}{l}\text { Growing urban centres from spontaneous } \\
\text { growth. }\end{array}$ \\
\hline 3 & edge (organic) & spread & $\begin{array}{l}\text { Old or new urban centres spawn additional } \\
\text { growth. }\end{array}$ \\
\hline 4 & road-influenced & $\begin{array}{l}\text { Road-gravity } \\
\text { dispersion, } \\
\text { breed }\end{array}$ & $\begin{array}{l}\text { Newly urbanized cell spawns growth along } \\
\text { transportation network. }\end{array}$ \\
\hline Throughout & slope resistance & slope & $\begin{array}{l}\text { Effect of slope on reducing probability of } \\
\text { urbanization. }\end{array}$ \\
\hline Throughout & excluded layer & User-defined & $\begin{array}{l}\text { User specifies areas resistant or excluded to } \\
\text { development. }\end{array}$ \\
\hline
\end{tabular}

Table 1. SLEUTH model growth types and respective coefficients
The calibration was performed progressively at the three spatial resolutions with regression metrics obtained at the end of each run as representing the goodness of fit between the simulated growth and actual growth. The final step of the SLEUTH modelling is prediction wherein the calibrated growth coefficients together with the historical trends are used to generate a future scenario, this representing a "continuation of historical urban growth without changing current conditions" (Clarke and Gaydos, 1998), i.e. a "business as usual" approach.

\section{RESULTS AND DISCUSSION}

\subsection{Urban expansion and linkages with road density and population}

The Landsat derived urban expansion map (Figure 2) showed significant expansion of the built-up area for Bangkok over the 30 years from 1987 to 2017 . It is readily seen that the expansion pattern is radially outwards, and towards inland from the city core which borders the coastline. The urban expanded area over the 30 years was $287.6 \mathrm{~km}^{2}$ out of Bangkok city's administrative area of $1564.5 \mathrm{~km}^{2}$.

The 30-year urban expansion map was assessed w.r.t. the 2017 road density map to analyze the intra-urban expansion patterns with road density. We partitioned the road density map into 5 grades using the Jenks natural breaks and then extracted the corresponding urban expanded areas within each grade. The road density grading and urban expansions area and rates are shown in Table 2.

\begin{tabular}{|c|c|c|c|}
\hline $\begin{array}{c}\text { Road density } \\
\text { grade }\end{array}$ & $\begin{array}{c}\text { Road density } \\
\text { ranges } \\
\left(\mathbf{k m} / \mathbf{k m}^{2}\right)\end{array}$ & $\begin{array}{c}\text { Urban expansion area } \\
\left.\mathbf{( k m}^{2}\right) \text { and relative } \\
\text { percentage }(\%)\end{array}$ & $\begin{array}{c}\text { Urban area } \\
\text { expansion } \\
\text { rate }\left(\mathbf{k m}^{2} / \mathbf{y r}\right)\end{array}$ \\
\hline 1 & $0-2.42$ & $16.7(5.8 \%)$ & 0.6 \\
\hline 2 & $2.43-7.05$ & $69.7(24.2 \%)$ & 2.3 \\
\hline 3 & $7.06-12.09$ & $88.2(30.7 \%)$ & 2.9 \\
\hline 4 & $12.10-17.23$ & $79.6(27.7 \%)$ & 2.7 \\
\hline 5 & $17.24-25.70$ & $33.4(11.6 \%)$ & 1.1 \\
\hline
\end{tabular}

Table 2. Urban expansion areas and rates versus the road density grades

As seen from Table 2, 83\% of the total intra-city expansion area of $287.6 \mathrm{~km}^{2}$ occurred over the road density grades of 2 to 4 , with grades of 1 and 5 having much small expanded areas. A similar pattern is seen for the expansion rates. To further assess the linkage between intra-city expansion rate and road density, we aggregated the expansion areas over road density bins of 0.1 $\mathrm{km} / \mathrm{km}^{2}$ and obtained an urban expansion rate versus road density plot shown in Figure 6 (a). The logarithm of the urban expansion rate with road density exhibited an inverted concave shape with the urban expansion rate initially increases with road density but subsequently drops. This is modelled using a third-order polynomial with a turning point (equations (1) and (2)). The turning point is interpreted as the threshold at which the effect of increasing road network density on promoting urban expansion changes, i.e. from increasing urban expansion rates to decreasing (Zhao et al., 2017). This turning point value for Bangkok is 12.08 $\mathrm{km} / \mathrm{km}^{2}$, a value between road density grades of 3 and 4 (Table 2).

A city zoning map is next generated based on the turning point value to identify regions that are before the turning point, i.e. before the peak urban expansion rate, and regions after. This zoning map is shown in Figure 7 wherein orange and yellow 
colors denote areas before and after the turning point, respectively, and with the urban expanded pixels (black) overlaid for reference. It is noted that while the turning point values computed here are based on expanded areas occurring within the three decadal timeframe, such maps as generated using different timeframes would be helpful in identifying the pre- and postturning point regions within each city and so can steer future intra-urban growth planning towards a more sustainable path by e.g. changes in the road density.
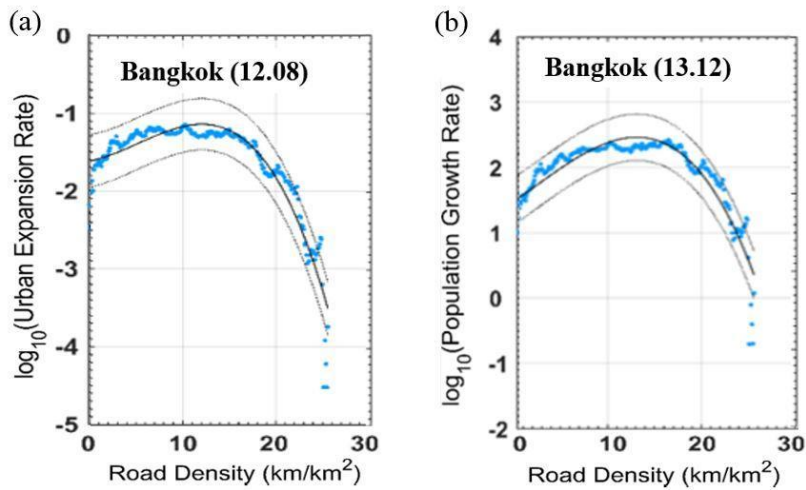

Figure 6. (a) Urban expansion rate and road density values and fitted using a third-order polynomial (upper/lower bounds in the

fit indicate $90 \%$ confidence intervals). (b) As (a) but for population growth rate. Turning point values $\left(\mathrm{km} / \mathrm{km}^{2}\right)$ are listed within parenthesis.

The population growth rate with road density is similarly assessed with results shown in Figure 6(b). The logarithm of population growth rate also has a similar inverted concave pattern with road density and fitted with the third order polynomial. This can be expected as urban expansion rates are tightly coupled with population growth patterns. The turning point threshold for population growth rate w.r.t. road density is $13.12 \mathrm{~km} / \mathrm{km}^{2}$, close to that for urban expansion. Also $79 \%$ of the expanded population have occurred over the road grades of 2 to 4 .

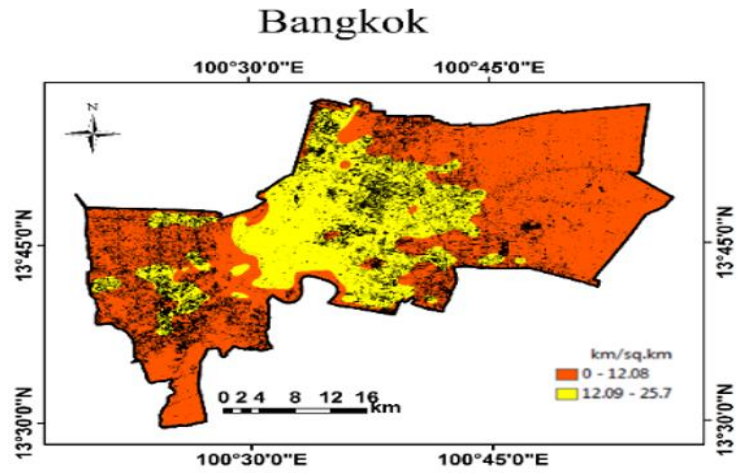

Figure 7. Zoning map for Bangkok based on turning point threshold. Overlaid black pixels indicate urban expanded areas.

\subsection{SLEUTH model results}

The SLEUTH model was calibrated with input datasets as described earlier with the final growth coefficients obtained after the final calibration run. The coefficient values are: Diffusion 2; Breed - 20; Spread - 22; Slope - 90; Road gravity - 20 as selected based on the Lee-Salee metric. This metric measures the degree of spatial match between the modelled extent and input data for each combination of variables. The metric value of 0.56 obtained during the final calibration indicated a successful calibration as consistent with reported studies (Clarke and Gaydos, 1998; Hua et al., 2014) using SLEUTH. These derived coefficient values were used in the predict function of the SLEUTH model with the final year 2017 urban layer as the seed layer from where the growth prediction variables propagated. Here, the growth prediction was run for 10 years, i.e. 2017 2027 , i.e. a total of 10 predicted urban layers where the urban expanded pixels can be readily analyzed. Figure 8 shows the predicted Bangkok growth for 2 years, namely 2018 and 2027.

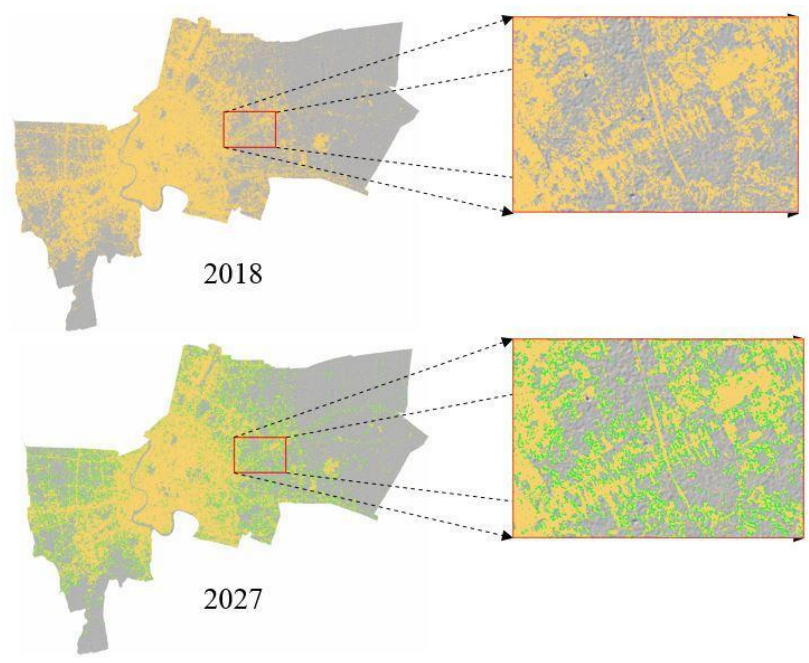

Figure 8. Urban growth prediction maps for Bangkok. Yellow colored pixels represent seed (2017) urban layer; green represent urbanized pixels at $80-94 \%$ probability. A small area is highlighted for clarity showing the expanded (green) pixels (Note: Map not drawn to scale).

The future growth pattern of Figure 8 shows that that the predicted growth follows a radially outward/edge-based transition from the seed (year 2017) layer pixels as was also observed for the historical (Figure 3). This growth being more representative in terms of edge growth/spreading outwards is attributed mainly to the spread coefficient value being higher than the breed, diffusion and road gravity coefficients. From the topography/hillshade data, it is evident that most of the Bangkok metropolis region is low-lying without significant topographic undulations which augments the spreading pattern observed from SLEUTH. Such behavior in urban land expansions is consistent with Losiri et al., (2016) who reported that most of the historical expansion is from conversion of agricultural lands in Bangkok's plains into urban areas.

Further, the future urban expanded pixels were accumulated and plotted temporally in Figure 9 where a linear trend is seen. The 10 -year projected expanded area of $129.9 \mathrm{~km}^{2}$ can be compared with the historical 30 -year of $287.6 \mathrm{~km}^{2}$ indicating a faster expansion rate going forward. 


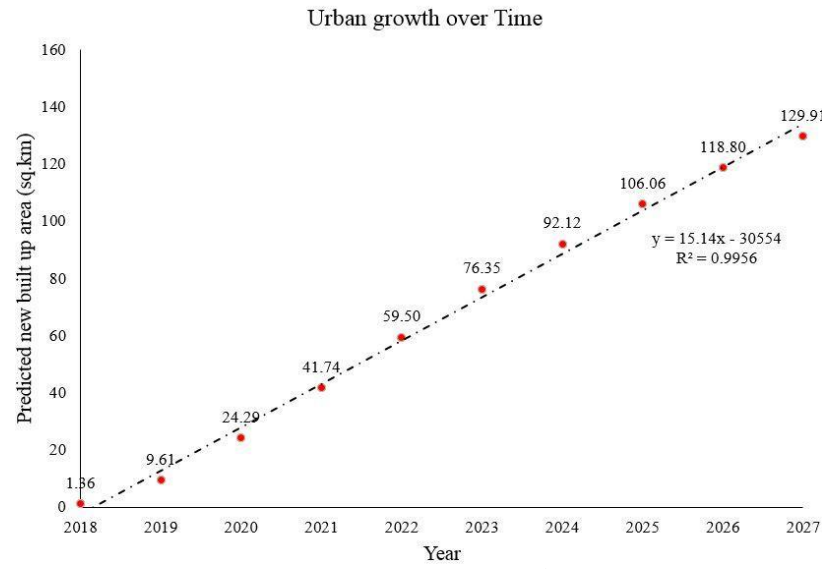

Figure 9. Predicted urban growth (in $\mathrm{km}^{2}$ ) from 2018 to 2027 for Bangkok.

The SLEUTH model prediction results were further analyzed w.r.t the road density turning point map developed earlier. The turning point highlighted the intra-city zones where the urban expansion with road density had rate behavior changing from increasing to decreasing. We divided the urban expanded pixels into two zones for all the 10 predicted years as based on the turning point threshold of $12.08 \mathrm{~km} / \mathrm{km}^{2}$. The accumulated urban expanded areas within these two zones for the 10 predicted years is shown in Figure 10.

Figure 10 shows the two trend lines of predicted urban expansion areas, occurring where the urban expansion rate was increasing with the increasing road density (i.e. below the turning point denoted by the red-dotted line) and where the rate was decreasing (i.e. after the turning point denoted by the yellow-dotted line). The trend line over areas after the turning point is consistently lower than areas before the turning point. It further flattens as the urban expansion within these areas are getting saturated over time with such areas mainly representing city core regions with new space for built up areas getting increasingly limited. Conversely the (red-dotted) trend line for areas below the turning point has its urban expansion rate increase initially with time before slightly levelling off, but still maintains a higher rate than the (yellow-dotted) trend line for areas after the turning point. These represent areas which are getting urbanized at a higher rate as spreading outward of the core city and would also indicate areas with an increased future infrastructure demand. Such areas should then be prioritized in terms of urban planning.

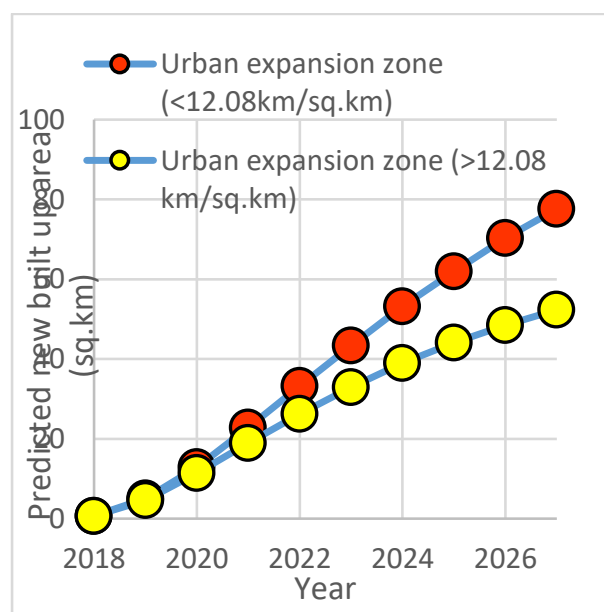

Figure 10. Predicted urban growth categorized and quantified w.r.t. road density turning point value.
Also, it is observed that about $82 \%$ of the total predicted area of $129.9 \mathrm{~km}^{2}$ (predicted built up area for 2027) have occurred over the current road grades of 2 to 4 which correlates well with the historical trend (1987-2017). Hence, SLEUTH modelling not only helps to identify probable new urbanization areas but together with road density turning point map and road density grades, be able to inform on the expansion rates as well as indicating areas needing additional road infrastructure to support the expansion.

\section{CONCLUSIONS}

Bangkok is continually growing as a major global metropolis in terms of population, economy and area as typical of many SEA cities. It is thus important to identify and assess the spatial urban growth, infrastructure and socio-economic patterns over time and also their linkages in order to better plan for future sustainable development. Towards this, the results presented herein as based on detailed spatial-temporal analysis of urban extents and road density provides for a quantification of the urban expansion process and its relationship with road density.

The results presented shows that Bangkok has a radially outward growing trend with around $287.6 \mathrm{~km}^{2}$ area expanded over a historical 30-year (1987-2017) period, and with a SLEUTH predicted expanded area of $129.9 \mathrm{~km}^{2}$ over 2017 to 2027 . This urban expansion was found to depend on derived road density grades with a predominant $83 \%$ of the urban expanded areas historically (1987-2017) and $82 \%$ projected (2017-2027) occurring over road density grades of 2 to 4 . The relationship between the intra-city expansion rate and road density exhibited an inverted concave pattern and readily modelled using a thirdorder polynomial with a turning point. Areas with read density before the turning point shows an increasing expansion rate with road density and vise-versa. The similar analysis using population growth rate also exhibited a similar relationship, with turning point value close to that from the urban expansion analysis, suggesting strong linkages between urban expansion and population growth rates. These trends, specifically those of the urban expansion with turning point and with road density grades also hold under the SLEUTH predicted future (to year 2027) urban growth.

This study highlighted that spatial-temporal analysis of urban extents and together with SLEUTH can provide useful information towards supporting sustainable development plans. The intra-city zoning map could help improve on urban planning as well as identify areas likely to require additional infrastructure. Follow-on studies should expand on the scope to include other SEA cities, analyze infrastructure beyond road networks, as well as using different urban growth models to confirm on the conclusions reached.

\section{ACKNOWLEDGEMENTS}

This study is supported by National Research Foundation Singapore - Future Resilient Systems programme. The first author also acknowledges graduate assistantship support from the Interdisciplinary Graduate Programme (IGP), Nanyang Technological University. We also thank the co-chairs of the PhilGEOS X GeoAdvances 2019 programme for giving an opportunity to submit full paper and participate in the conference. 


\section{REFERENCES}

Almazroui, M., Mashat, A., Assiri, M.E., Butt, M.J., 2017. Application of Landsat Data for Urban Growth Monitoring in Jeddah. Earth Syst. Environ. 1, 25. https://doi.org/10.1007/s41748-017-0028-4

Al-shalabi, M., Billa, L., Pradhan, B., Mansor, S., Al-Sharif, A.A.A., 2013. Modelling urban growth evolution and land-use changes using GIS based cellular automata and SLEUTH models: the case of Sana'a metropolitan city, Yemen. Environ. Earth Sci. 70, 425-437. https://doi.org/10.1007/s12665-012-2137-6

Batty, M., 2007. Cities and Complexity: Understanding Cities with Cellular Automata, Agent-Based Models, and Fractals. The MIT Press.

Bhatta, B., 2009. Analysis of urban growth pattern using remote sensing and GIS: a case study of Kolkata, India. Int. J. Remote Sens. 30, 4733-4746. https://doi.org/10.1080/01431160802651967

Bihamta, N., Soffianian, A., Fakheran, S., Gholamalifard, M., 2015. Using the SLEUTH Urban Growth Model to Simulate Future Urban Expansion of the Isfahan Metropolitan Area, Iran. J. Indian Soc. Remote Sens. 43, 407-414. https://doi.org/10.1007/s12524-0140402-8

Bishop, I.D., Escobar, F.J., Karuppannan, S., Suwarnarat, K., Williamson, I.P., Yates, P.M., Yaqub, H.W., 2000. Spatial data infrastructures for cities in developing countries: Lessons from the Bangkok experience. Cities 17, 85-96.

Catalán, B., Saurí, D., Serra, P., 2008. Urban sprawl in the Mediterranean?: Patterns of growth and change in the Barcelona Metropolitan Region 1993-2000. Landsc. Urban Plan. 85, 174-184. https://doi.org/10.1016/j.landurbplan.2007.11.004

Cauwels, P., Pestalozzi, N., Sornette, D., 2014. Dynamics and spatial distribution of global nighttime lights. EPJ Data Sci. 3, 1.

Chand, T.R.K., Badarinath, K.V.S., Elvidge, C.D., Tuttle, B.T., 2009. Spatial characterization of electrical power consumption patterns over India using temporal DMSP-OLS night-time satellite data. Int. J. Remote Sens. 30, 647-661. https://doi.org/10.1080/01431160802345685

Chen, M., Zhang, H., Liu, W., Zhang, W., 2014. The Global Pattern of Urbanization and Economic Growth: Evidence from the Last Three Decades. PLoS ONE 9, e103799. https://doi.org/10.1371/journal.pone.0103799

Clarke, K.C., Gaydos, L.J., 1998. Loose-coupling a cellular automaton model and GIS: long-term urban growth prediction for San Francisco and Washington/Baltimore. Int. J. Geogr. Inf. Sci. 12, 699714. https://doi.org/10.1080/136588198241617

Elvidge, C.D., Hsu, F., Baugh, K.E., Ghosh, T., 2014. National Trends in Satellite-Observed Lighting. Glob. Urban Monit. Assess. Earth Obs. 97-118.

Florida, R., Fasche, M., 2017. The Rise of the Urban Creative Class in Southeast Asia. Martin Prosper. Inst. 60.

Henderson, V., 2003. The urbanization process and economic growth: The so-what question. J. Econ. Growth 8, 4771.

Herold, M., Goldstein, N.C., Clarke, K.C., 2003. The spatiotemporal form of urban growth: measurement, analysis and modeling. Remote Sens. Environ., Urban Remote Sensing 86, 286-302. https://doi.org/10.1016/S0034-4257(03)00075-0
Hua, L., Tang, L., Cui, S., Yin, K., 2014. Simulating Urban Growth Using the SLEUTH Model in a Coastal PeriUrban District in China. Sustainability 6, 3899-3914. https://doi.org/10.3390/su6063899

Imhoff, M.L., Lawrence, W.T., Stutzer, D.C., Elvidge, C.D., 1997. A technique for using composite DMSP/OLS "City Lights" satellite data to map urban area. Remote Sens. Environ. 61, 361-370. https://doi.org/10.1016/S0034-4257(97)00046-1

Kamarajugedda, S.A., Mandapaka, P.V., Lo, E.Y.M., 2017. Assessing urban growth dynamics of major Southeast Asian cities using night-time light data. Int. J. Remote Sens. 38, 6073-6093. https://doi.org/10.1080/01431161.2017.1346846

Liu, Z., He, C., Zhang, Q., Huang, Q., Yang, Y., 2012. Extracting the dynamics of urban expansion in China using DMSP-OLS nighttime light data from 1992 to 2008. Landsc. Urban Plan. 106, 62-72. https://doi.org/10.1016/j.landurbplan.2012.02.013

Losiri, C., Nagai, M., Ninsawat, S., Shrestha, R.P., 2016. Modeling Urban Expansion in Bangkok Metropolitan Region Using Demographic-Economic Data through Cellular Automata-Markov Chain and Multi-Layer Perceptron-Markov Chain Models. Sustainability 8, 686. https://doi.org/10.3390/su8070686

Ma, T., Zhou, Y., Zhou, C., Haynie, S., Pei, T., Xu, T., 2015. Night-time light derived estimation of spatio-temporal characteristics of urbanization dynamics using DMSP/OLS satellite data. Remote Sens. Environ. 158, 453-464. https://doi.org/10.1016/j.rse.2014.11.022

Mallouk, A., Elhadrachi, H., Malaainine, M.E.I., Rhinane, H., 2019. USING THE SLEUTH URBAN GROWTH MODEL COUPLED WITH A GIS TO SIMULATE AND PREDICT THE FUTURE URBAN EXPANSION OF CASABLANCA REGION, MOROCCO. ISPRS - Int. Arch. Photogramm. Remote Sens. Spat. Inf. Sci. XLII-4/W12, 139-145. https://doi.org/10.5194/isprs-archives-XLII-4-W12139-2019

Masek, J.G., Lindsay, F.E., Goward, S.N., 2000. Dynamics of urban growth in the Washington DC metropolitan area, 1973-1996, from Landsat observations. Int. J. Remote Sens. 21, 3473-3486.

Pandey, B., Joshi, P.K., Seto, K.C., 2013. Monitoring urbanization dynamics in India using DMSP/OLS night time lights and SPOT-VGT data. Int. J. Appl. Earth Obs. Geoinformation 23, 49-61. https://doi.org/10.1016/j.jag.2012.11.005

Pumain, D., 2004. Scaling laws and urban systems. SFI Work. Pap.

Saxena, A., Jat, M.K., 2019. Capturing heterogeneous urban growth using SLEUTH model. Remote Sens. Appl. Soc. Environ. 13, 426-434. https://doi.org/10.1016/j.rsase.2018.12.012

Seto, K.C., 2011. Exploring the dynamics of migration to megadelta cities in Asia and Africa: Contemporary drivers and future scenarios. Glob. Environ. Change 21, S94S107. https://doi.org/10.1016/j.gloenvcha.2011.08.005

Seto, K.C., Güneralp, B., Hutyra, L.R., 2012. Global forecasts of urban expansion to 2030 and direct impacts on biodiversity and carbon pools. Proc. Natl. Acad. Sci. 109, 16083-16088.

Strano, E., Nicosia, V., Latora, V., Porta, S., Barthélemy, M., 2012. Elementary processes governing the evolution of road networks. Sci. Rep. 2, 296. https://doi.org/10.1038/srep00296 
Subasinghe, S., Estoque, R., Murayama, Y., 2016. Spatiotemporal Analysis of Urban Growth Using GIS and Remote Sensing: A Case Study of the Colombo Metropolitan Area, Sri Lanka. ISPRS Int. J. Geo-Inf. 5, 197. https://doi.org/10.3390/ijgi5110197

Triantakonstantis, D., Mountrakis, G., 2012. Urban Growth Prediction: A Review of Computational Models and Human Perceptions. J. Geogr. Inf. Syst. 04, 555-587. https://doi.org/10.4236/jgis.2012.46060

UNPD, 2018. United Nations,Department of Economic and Social Affairs, Population Division, World Urbanization Prospects: The 2018 Revision: Key Facts.

Wilson, E.H., Hurd, J.D., Civco, D.L., Prisloe, M.P., Arnold, C., 2003. Development of a geospatial model to quantify, describe and map urban growth. Remote Sens. Environ., Urban Remote Sensing 86, 275-285. https://doi.org/10.1016/S0034-4257(03)00074-9

Yang, X., 2002. Satellite monitoring of urban spatial growth in the Atlanta metropolitan area. Photogramm. Eng. Remote Sens. 68, 725-734.

Zhang, Y., Li, X., Wang, A., Bao, T., Tian, S., 2015. Density and diversity of OpenStreetMap road networks in China. J. Urban Manag. 4, 135-146. https://doi.org/10.1016/j.jum.2015.10.001

Zhao, G., Zheng, X., Yuan, Z., Zhang, L., 2017. Spatial and Temporal Characteristics of Road Networks and Urban Expansion. Land 6, 30. https://doi.org/10.3390/land6020030

Zhao, M., Cheng, W., Zhou, C., Li, M., Huang, K., Wang, N., Zhao, M., Cheng, W., Zhou, C., Li, M., Huang, K., Wang, N., 2018. Assessing Spatiotemporal Characteristics of Urbanization Dynamics in Southeast Asia Using Time Series of DMSP/OLS Nighttime Light Data. Remote Sens. 10, 47 https://doi.org/10.3390/rs10010047

Zhou, Y., Wang, Y., Gold, A.J., August, P.V., Boving, T.B., 2013. Assessing impact of urban impervious surface on watershed hydrology using distributed object-oriented simulation and spatial regression. GeoJournal 79, 155166. https://doi.org/10.1007/s10708-013-9506-x 